\title{
CHINA'S ENVIRONMENTAL CRISIS
}

\author{
CHARLES F. BINGMAN
}

Consider the judgments of official sources and expert opinions ${ }^{1}$ both in China and from the outside, about China and the environment:

* Agricultural runoff is "the worst in the world"

* Soil erosion is "the worst in the world"

* Desertification is "the worst in the world"

* Air pollution: China is the world’s largest producer of carbon dioxide

* China has 16 of the 20 world's most polluted cities

* China suffers from "the worst river water cessation in the world"

* The Yellow River is the most silt clogged in the world

* China is the world's largest user of coal, the world's largest producer of carbon dioxide, and acid rain falls in one third of the country

* Almost every river in the country is heavily polluted

* $25-40 \%$ of all mercury emissions in the world come from China

* Only $20 \%$ of waste water is treated

* In the last half century, 332 Chinese dams have failed, including "the worlds worst dam disaster" - the Banqiao and Shimanan dams in Henan Province which collapsed and killed an estimated 80,000 to 200,000 people.

* 300 of China's 600 largest cities (and 400 out of 700 villages studied) suffer from serious water shortages - and the shortages are chronic. 65\% of underground aquifers in the

\footnotetext{
Charles F. Bingman is a retired Fellow of the Johns Hopkins University Washington Center for the Study of Government. His background includes 30 years as a Federal government executive. He has undertaken consulting assignments in the U. S. and in 11 other countries including China. (2010). He is an elected Fellow of the National Academy of Public Administration.

${ }^{1}$ See environmental analyses in the following sources which were used to research this paper: Becker, Jasper, "The Chinese” pp. 33-41; Bergsten, Fred C. et al, “China’s Rise”, 152-156; Chow, Gregory C., “China’s Economic Transformation”, pp. 187-192; Economy, Elizabeth, “China's Coming Environmental Crash”, Foreign Affairs Journal, Sept./Oct. 2007; Friedman, John, “China’s Urban Transition”, pp. 124-126; Gittings, John, “The Changing Face of China”, pp. 284-289; Harney, Alexandra, “The China Price”, pp. 88-101; Hutchings, Graham, “Modern China: A Guide to a Century of Change”, pp. 124-127; Pei, Minxin, “China’s Trapped Transition”, pp.175-176; Schell, Orville, and Shambaugh, David, “The China Reader”, pp.376-393; Shirk, Susan, “China: Fragile Super Power”, pp. 32-34; Starr, John B., “Understanding China”, pp. 176-191; World Bank, “China 2020” pp. 71-81, reports of China's State Environmental Protection Administration (SEPA), State Forestry Administration, Ministry of Construction, Xinhua News Agency, Ministry of Public Health.
} 
major 118 cities are "severely polluted". In Beijing, 90\% of the underground sources of water have been used up. This listing could go on and on.

In fact, in every one of these environmental disaster areas, the situation is getting worse and not better.

Economic development in China means breakneck urbanization, heavy concentration on manufacturing, greatly expanded coal fired electrical power generation pollutants, heavy metals dumped into the air, and nasty chemicals dumped into the water. Heavy metals in the water are highly concentrated - 2,000 times as high as the official government standard. Japan and Korea are suffering from acid rain produced by China's coal power electricity plants, and from dust storms carrying toxic dust. Scarce water resources are simply being recklessly dissipated. All of these problems are heavy contributors to environmental failures and crises, and all have been known by the government from the very beginning. The problem of environmental pollution was first addressed at a national conference on the subject in 1973, and six years later, the National People's Congress passed the Environmental Protection Law. Five years after that, in 1984, the National Environmental Protection Agency (NEPA) was formed. In 1998 it was promoted to ministerial level as the State Environmental Protection Administration (SEPA) under the State Council. The law was amended to require environmental impact studies for all major construction projects and for imposing stiff fines for violations. Many environmental groups were started, and public opinion polls were almost unanimous in calling for stricter enforcement.

But despite all of these official efforts, extraordinarily little has ever really been done. Environmental issues seem particularly difficult to resolve in the Chinese political system because of the continuing clash with economic development goals and understandable conflict with local governments over the money problem. So all environmental problems continue to get worse.

The Chinese Communist Party (CCP) has issued its $11^{\text {th }}$ "Five Year Program” in 2005 which calls for a 20\% improvement in energy efficiency by 2010. Energy efficiency is a very expensive, highly technical and long term activity, and there seems to be no adequate explanation of how the Chinese could achieve this goal. "Socialist industrialization" was highly wasteful; because land and water were government owned they were given away usually free in the name of economic development, and recklessly squandered. Water and energy have been supplied to favored cities either free or at highly subsidized rates. All governments and most State Owned Enterprises (SOEs) had positive motives to consume assets if it will produce more profit.

Nor is this really a matter of China being a poor country. The government now has large sums of money that it can deploy, but environmental problems continue to be low priority. The national government avoided responsibility by “delegating” responsibility for environmental problems to local governments - provinces, townships, counties and cities. But at the time, all of these jurisdictions were still very poor and seriously disorganized after the Maoist neglect. ${ }^{2}$ The commune system displaced much of the normal government apparatus with amateur

\footnotetext{
2 Hutchings, Graham, “Modern China”, pp. 124-127. Harvard U. Press, 2001. Also Schell, Orville, and
} Shambaugh, David, “The China Reader”, p. 380, and ; Gittings, John, “The Changing Face of China”, p. 284. 
incompetents, and forced pathological practices on the country. For example, hundreds of thousands of valuable trees were simply cut down to provide fuel for hundreds of thousands of back yard iron smelting furnaces, which were a total failure. It is true that deforestation had been going on for centuries, but the Maoist era simply made it very much worse very fast. Unrealistic production quotas forced overproduction, land wastage, more forest clearing, production of the wrong things, and the wasting of huge sums of scarce funds. Terracing and irrigation were rapidly expanded, often with disastrous consequences. Dams, terraces, reservoirs and cisterns were so poorly built that many quickly collapsed or have been abandoned, since they often served marginal land that had low production potential and high costs. Activities in the hands of collectives have been better, but still amateurish and exposing low managerial abilities. Beijing has reacted typically: the government kept announcing bold new "30 Year Plans", but everybody knew that local governments have never had the money to implement them. In fact, there has never had a sufficiently sturdy source of funds for environmental problems, and the national government has never had any intention of filling the gap. The CCP likes to point out that it is "spending more than $\$ 10$ billion on environmental concerns", which is truly a pitiful trivial sum. In addition, the CCP has also developed a tendency to shift part of the blame onto "multi-national corporations". But this is merely classic CCP thinking - find somebody else to blame, and conceal your own sins. "China's environmental problems stem as much from China's corrupt and indifferent political system as from Beijing's continued focus on economic growth. Local officials and enterprise leaders routinely - and with impunity - ignore environmental laws and regulations, illegally reallocate environmental protection funds or simply steal them. ${ }^{3}$

In case after case, huge environmental problems have been documented, but this simply highlights the real issue: nobody in China is capable of dealing with the enormity of these problems. Instead, the government continues to issue bland political promises, Five Year Plans, Thirty Year Plans, and new laws and regulations, and to criticize local governments because they have not yet "solved" the problems. These plans and pronouncements are political cover for the fact that governments choose to provide only pitifully inadequate funding. All of this is deliberate. The CCP fully recognizes the heart of their dilemma: environmental problems are enormously costly, and they are heavy potential counter demands against the dominant policy of spending on economic development which is at the heart of the CCP's survival strategy.

The local governments feel that they have been unfairly stuck with these problems with absolutely no help from anybody else. The SOEs were never involved. The private sector doesn't want the added expense or the responsibility. The whole manufacturing sector of the economy is still highly inefficient. Many SOEs have long histories of running at a deficit and having to be propped up by the government. Many private enterprises are running on very thin profit margins and maintain that they can't afford any more expensive responsibilities. There are too many competitors struggling to stay alive, and they often feel they have to conceal their real situation from the government. Many environmental problems are ancient: floods, droughts, overgrazing, desertification, soil erosion, mining wastes. But there are also new problems that are a direct consequence of the economic development programs such as hundreds of thousands of new industrial sites dumping pollutants into the air or water; millions of new automobiles;

3 Economy, Elizabeth, "China's Coming Environmental Crash”, Washington, D. C., Foreign Affairs September/October, 2007, p. 56. 
accelerating exhaustion of water resources; and wastage of energy and raw materials. Over expansion of cities has created rapidly growing urban problems. Lack of raw materials and energy tends to drive up prices. While China's government benefits greatly from foreign sales, it has not yet made satisfactory progress in meeting the consumer needs of its own people.

But instead of a serious national environmental program, the government has chosen to bob and weave, and its actual priorities include spending at least \$24 billion on the Three Gorges dam project, and perhaps another \$16 billion on the South to North Water Diversion Project, which, even if justified, will create large and highly complex new environmental problems. The railroad line to Tibet cost a fortune, and another fortune is to be sunk in a "bullet train" from Beijing to Shanghai, and there always seems to be enough money to subsidize its inefficient SOEs.

The success of economic development is vital to the survival of the CCP itself, and this cannot and will not be changed any time soon. Economic development has been the compelling and overpowering driver in China for almost 35 years. Because of this, China will not stop burning coal and creating acid rain. It will not willingly close industrial plants that pollute the air unless there is the risk of fatal political disaster. The CCP will not reverse its policy of dumping environmental problems on local governments, nor will it fund these governments. Neither the CCP nor anybody else has any idea of what to do about desertification, soil erosion and river silting, and even if they did, these problems are so enormous and complex that they are simply "mission impossible". Urban air pollution is not being dealt with, and in fact, is getting worse every day, and in more cities lung diseases now kill more people than any other cause. The depletion of urban underground water aquifers is permanent and irreversible, and the exhaustion of these resources is speeding up. Urban expansion requires more water resources, urban sanitation, waste water treatment and other public services. It also means the rise in the number of households, millions of urban transportation trips, huge truck traffic to bring in supplies, vastly increased oil and gas consumption, and heavy and unremitting construction activity.

As an example, Friedman summarized the conclusions of a study of the city of Wuhan, in the late 90 s, a city and region of about 7 million people. “The city's environment is seriously degraded, with an urgent need to treat high concentrations of sulphur dioxide, nitrogen oxides, and dust fallout. Much of its surface waters are highly polluted, resulting largely from poor treatment of wastewater. In all areas there is an urgent need for improvement. Although pollution from rural industries will increase in the coming years, the main polluters remain the city/state owned enterprises. Wuhan has a detailed and complex system of laws and regulations covering most areas, combined with a framework of environmental monitoring, and a system or rewards, sanctions and environmental funding. But this system is so inadequately enforced that it fails to meet the city's current environmental needs. Standards issued by environmental departments are often ignored by the SOEs. The impact of environmental planning is limited by being implemented at too general a level and public information and education is poor. Environmental impact assessment seems to be of poor quality. There is a lack of funds and a lack of clarity in requirements. Pollution fines are set too low." In other words, the city government set all of the legal and bureaucratic apparatus in place, but then lacked the courage and the will to use its own tools.” 


\section{Has the CCP Finally Come Around?}

It was not until the late 90s that the CCP appeared finally to wake up, and that is only because it finally began to realize the heavy economic penalties it created by its pathological neglect of environmental degradations. ${ }^{4}$ But the basic dilemma remains for the CCP: how can it meet these increasingly urgent demands without retrenching its economic development commitments?

Most of the older industrial base and energy production facilities, and even the newer manufacturing plants were designed and built with absolutely no thought to their environmental impact. Many are highly inefficient, environmental issues aside. Most are energy guzzlers, using 8 to 10 times the energy per unit of output compared to that of modern plants elsewhere. In other words, "fixing" the environmental problems of SOEs is a monumental problem embedded in an even more monumental problem of upgrading the SOEs themselves. SOEs, which were the great bulk of industrial production through the early 90s, were never even permitted to deal with environmental concerns because of the potential costs; the government recognized that up to $50 \%$ of SOEs were operating at a deficit, and many others were economically marginal. Few could bear the additional costs of environmental protection. In fact, the government often subsidized these SOEs not only with money, but with free water, free land and highly subsidized energy. As a result, the industrial and energy sectors of the economy were highly wasteful and polluting, and environmentally ignorant.

The SOE base for the economy has been extensively restructured by a program of "divestiture" which as purged SOEs in several ways: by consolidation, privatization, transfer to local governments, by setting them loose, or by simple elimination. Those thousands of SOEs that have been retained have been the subject of intense "management improvement" reforms and overall this has resulted in general economic improvement but it has not meant that any environmental problems have been solved. If SOEs were combined or consolidated, the new enterprises still faced all of the old problems. Where SOEs were devolved to provinces, townships or municipalities, those governments inherited the environmental sins as well.

Much of what is now being developed such as farming, pulp and paper mills, coal mining, chemical factories, tanning and dyeing plants, small scale manufacturing are high polluting enterprises, and their runoffs are going untreated into rivers and streams, and their solid waste is forming new mountains. There are hundreds of thousands of these little operations, mostly township/village enterprises (TVEs) run by government people or government sponsored collectives, and many of them are only marginally profitable. What is the prospect of fighting through local political resistance and getting all of these little marginal enterprises to clean up their act? It is nonsense to expect local governments to tackle more than local problems, and most of the worst problems are countrywide in scale, begging for national solutions. Every river basin encompasses dozens of provinces, counties and cities. Air pollution not only effects all 600 of the largest cities but has "fallout" consequences in Japan, the Koreas and even the United States and Canada. Farming takes place in every province, but if there is a solution for desertification and land silting and chemical runoffs, it will have to be paid for by eastern cities.

\footnotetext{
${ }^{4}$ Minxin Pei in his book “China’s Trapped Transition” estimates 7.7\%. Elizabeth Economy in her article in the Foreign Affairs Journal estimates from 8 to $12 \%$.
} 
Policing of hundreds of thousands of polluting factories cannot be left to the varying capacities of more than 700,000 local political jurisdictions.

\section{The Most Desperate Crisis: Water}

The enormity of the problems can best be illustrated by the almost desperate future China faces over water resources. ${ }^{5}$ For example:

* Two thirds of the water in underground aquifers in the 118 major cities is "severely polluted”.

* $75 \%$ of all lakes and about half of the rivers are heavily polluted, in some cases, so badly that the water can't even be used for farming or industrial purposes.

* Only $20 \%$ of waste water, both rural and urban is treated (compared to $80 \%$ in developed countries).

* Water supply is already very low on a per capita basis - about $25 \%$ of the world average

* Those underground aquifers in cities are not only being polluted, but they are being exhausted. Almost every city in China faces an increasingly ominous future about the adequacy of its water supply. In some coastal cities, when underground aquifers are drawn down, they may be penetrated by seawater pollution which is permanent and irreversible.

* Water usage is highly inefficient. Irrigation consumes two thirds of China's water resources, and more than half of this water is wasted by terracing, faulty irrigation systems and poor water management. In addition, irrigation has produced high levels of salinity in more than $10 \%$ of all land.

Industrial plants have never been asked to be water efficient, and in fact, the government has often provided free or subsidized water to its favored SOEs. The unit cost of water is 15 times higher than in developed countries, and 25 times higher than in Japan, and higher even than in India and Pakistan. Chinese factories use ten times more water than most developed countries to produce the same products, and Chinese irrigation uses twice as much. By contrast, the U. S. has actually experienced the growth in its economy without increasing water use.

The Chinese government certainly knows about these threats but has essentially chosen to ignore them until very recently. Even where the government is now acting, it is not certain that they will succeed. Take the case of the Yellow River, one of the two most important in China. "The Yellow River began to run dry at some times as early as 1985 . Now, each year, it gets worse. In 1997, it ran out of water 600 miles short of the sea, for 9 months. In 2001 it had dried up again before reaching the sea - the $4^{\text {th }}$ time in 10 years. The tributary Fen River is dry all year, except for a few weeks. The Yellow River valley contains 130 million people, and in total, a half a billion people depend on it for water and crop irrigation. As the rivers have dried up, people have had to go miles away from home to get drinking water from some neighboring town. This appears to be one of those big problems that never seem to be recognized by any government. There are many dams, and they displaced hundreds of thousands of residents, but

\footnotetext{
${ }^{5}$ See sources as listed in footnote 1.
} 
27 new dams are planned. In many cases, when populations are displaced, the government promises to take care of the displaced people, but then does so inadequately or not at all. And engineers agree that the Yellow River problems have yet to reach their peak. The CCP resisted these warnings for more than 40 years well into the 90 s, and their policy did not begin to shift until the end of the decade. On the upper reaches of the river, lakes are disappearing and in the middle portion, irrigation canals are running dry, fields are lost, desert areas are growing, wind storms are common and cover vast areas of China, Japan and S. Korea. In Shandong on the river delta, more than half of the water for irrigation is now drawn from underground sources but these are being drained for urban use twice as fast as the river and rainwater are replacing it. ${ }^{6}$ The Yangtze River, China's most important, is $60 \%$ polluted, including water from feeder rivers, and its soil discharge exceeds the Nile and the Amazon combined. The slogan "when the Yellow River runs clear" has the same connotation as "when Hell freezes over".

Many problems were created or exacerbated by Maoist mistakes in cutting down forests, expanding farm terracing, building dams which interfered with natural river flow, or expanding industrial consumption of coal. The world's worst dam failure, the Banqiao and Shimantan dams in Henan Province, was a dam that Mao ordered as a monument to his regime. Both dams, along with numerous smaller dams broke completely in August 1975 causing the death of from 86,000 people in the official estimates, to more than 225,000 according to opponents of the project. In Henan Province alone, 110 dams were thrown up in the 50s and 60s, but many were simply earth barriers, and more than half of them had collapsed by 1966. The Shimantan Dam was completed in the 1950s after more than 400,000 people were expelled from their homes. Within 2 years, silt had filled the reservoir behind the dam with mud up to the brim, and the mud eventually backed up through the reservoir for 60 miles, causing upstream flooding.

Or take the case of the Three Gorges Dam project. Aside from the assessment of the project itself, here is what Gittings ${ }^{7}$ reported: "The Ministry of Water Resources not only functions as a government department in charge of the project, but is also what is called a "benefit group". This means that once the department has won the right to build a project, they can use the project funds any way they want, without monitoring or supervision. Before the project was even approved, people in the department had already used project money to buy fancy cars and to build cottages and houses in Beijing for themselves. They spent about $1 / 20^{\text {th }}$ of the entire budget even before the project was approved or construction started. The "benefit group" seized the opportunity to promote the idea of building this controversial dam. At the same time though, eminent scholars and scientists, the best minds in China, had grave doubts about the technical and economic viability of the dam. They imagined that the government would allow an open discussion about the project, but they were wrong. They underestimated the strong resistance the benefit group would put up when facing criticism that threatened to break their "golden rice bowl". People in the department saw an opportunity to get money and promotions, so they really fought back. The order came from the top that no newspaper or magazine was allowed to run articles by scholars critical of the dam. The world's largest hydroelectric project, the dam would cost an estimated $\$ 24$ billion and create the $600 \mathrm{~km}$ reservoir, and would generate up to 18,000 megawatts of hydroelectric power. The dam itself

\footnotetext{
${ }^{6}$ Economy, Elizabeth, ibid.

${ }^{7}$ Gittings, John, “The Changing Face of China”, p. 286. Oxford U. Press, 2006.
} 
would be $2.3 \mathrm{~km}$ wide with a spillway at the center, powerhouses on either side and new navigation locks. It has been justified both on the grounds that it would alleviate flooding downstream in the central Yangtze valley, and that it would generate "clean power" to meet future economic demand. Displacement of people would reach an estimated 1.2 million, and there are sincere promises that they will be "taken care of". All of these enormous public commitments were made in the back room, with little public debate tolerated.

One of the strongest objections to dams of this size is that they are liable to cause rapid silting upstream so that their useful life will be greatly reduced. So in order to deal with this problem, it was concluded that four new upstream dams would be necessary on the tributary Jinsha River. Similar dam construction on the Mekong can affect four of China's downstream neighbors.

The Chinese government is developing what is called the "South to North Transfer Project" which plans to set up three transfer routes from the Yangtze River in the south to the Yellow River in the north. One transfer route is near the end of both rivers, where an existing reservoir will be enlarged and a 200 foot wide channel will be dug. The second route will be from Shandong to Tianjin. The third will be near the headwaters of both rivers where a 65 mile tunnel will be dug. But this whole scheme has a certain fantasy quality about it. It would take almost unthinkable amounts of money (about \$16 billion has already been committed) and long periods of time for activation, and it is not yet been made clear how more water would solve the pollution problems that are the major dilemma. The main objective of the project seems to be to solve the water shortages in Beijing, but it is difficult not to conclude that the grand scheme is not likely to be a serious solution to anything.

\section{Protecting the Land}

The environmental problems stemming from China's land are as ancient and intractable as those of the waters. For hundreds of years, Chinese farmers had been farming the land in ways that produced a long term balance, but China has never had enough land to grow enough food and its farming and Mao pushed farming to the limits by relying too heavily on destructive terracing of hillsides and excessive crop irrigation systems, especially for rice. Thus, whatever balance existed has been shattered in the modern era. China's population has more than doubled in the Communist era despite the one child policy and this has created a genuine government urgency (i. e. panic) to increase production of food. Second, new farming technology created exactly this potential and the government thought/hoped to get it adopted. Third, industrialization began to compete for land and water, especially in areas next to cities. The "socialist" nature of this industrialization was such that it was very wasteful and low efficiency and thus offered no incentive to conserve or to be efficient. Resources such as timber, coal, other minerals, and water were ruthlessly exploited, and have left the country with the serious consequences of this waste. A lot of the pollution in the past was caused by SOEs and collectives, all of which saw themselves as excused from environmental responsibilities, and since so many of them were loss making, the political leadership has been reluctant to increase their expenses. This discouraging situation has not developed because of a lack of agencies, laws, or regulations. On the contrary, China has a reasonably complete set of environmental 
protection laws and regulations and a fully articulated structure of government offices devoted to environmental matters, whose principal role is to maintain a façade of credibility.

Part of the problem appears to be the usual intergovernmental tangle. First is the unfunded mandate problem, where large new responsibilities have been assigned to local governments with no money authorized to pay for them. Then there is a more traditional level of bureaucratic conflict between local governments and Beijing. There is also the conflict at the local government level between environmental organizations and other government departments. Finally, there is the usual conflict between the government and the separate CCP political channels.

China's provinces, town, and villages have always attempted to deal, however ineffectively, with these ancient land and water problems, but they can no longer cope with their escalation, and most are facing grim environmental futures. The CCP has chosen to avoid its responsibilities at the national government level by "delegating” responsibility for environmental matters to local governments, knowing full well that most of the problems are countrywide and not local. But local governments might still produce some limited solutions in the use and conservation of land because they are the creators of most problems. One third of Chinese land suffers from serious soil erosion, but provinces can, if they have the will, begin to prevent excessive terracing, and help farmers develop other land preservation techniques. Erosion is not just bad - it ranks among the worst in the world. Deforestation contributes heavily to erosion and it is losing huge areas of land to desertification; one quarter of the entire country is now a desert. Land losses reduce food production capacity just when it is most needed. Droughts seem to be getting worse; they used to occur every few years, but now occur almost every year. Irrigation is hugely wasteful of water, and it is now producing extensive salinity and pollution through runoffs of fertilizers and pesticides. Further losses of land stem from overgrazing, and the new modern threat - usurpation of farm land for urban and industrial expansion. Local governments at all levels are harsh exploiters of land which can be leased for economic development which produces major revenues, and they have little compunction about stealing land from farmers and ignoring the growing threats from environmental degradation.

\section{Danger in the Air}

The most "modern" of China's environmental disasters is in the air. The amounts of dangerous chemicals pumped into the air are now staggering. China is now the world's largest producer of carbon dioxide. Air pollution also includes excessive and illegal levels of sulphur dioxide, chlorofleurocarbons, smoke, dust and soil. Even the government's own State Environmental Protection Administration (SEPA) admits that this is true, and that air pollution is getting worse, not better. It is typical that the Chinese government now has a full array of nicely drafted laws and regulations "controlling” air pollution, and there are standards setting limits for every form of emission. But two thirds of China's cities that have been tested cannot meet these standards, or similar standards set by the World Health Organization. Nor does anybody seem to have a clue how this pollution can be brought under control. On the contrary, the whole vast tide of industrialization and urbanization is guaranteed to make matters very much worse very fast. One needs only to think about the millions of new automobiles and trucks and airplanes, and the 
development of an additional 562 new coal fired power plants, and the addition of many thousands of new or expanded industrial facilities to realize what is making air pollution worse.

Finally, and most typically, these environmental disasters pose ever increasing threats to the health of China's citizens. An estimated 190 million Chinese have had illnesses connected with drinking contaminated water. Cities and villages alike have suffered from repeated epidemics of diarrhea, and heightened rates of cancer, tumors, poisoning from lead, mercury and other heavy metals. Air pollution alone is said to have been the cause of up to 300,000 deaths. Once again, China's record is worse than any other country on earth. Beijing has six times higher air pollution rates than New York. Past dust storms are so persistent and severe that many people in cities wear face masks against dust and chemicals. There are huge worker time losses from lung diseases, blood infections, heart diseases, strokes and diabetes. There are about 24 million cars today, but in 20 years there may be upwards of 100 million, most of them in already choking cities. $60-90 \%$ of rain in Guandong province is acid rain, and farmland losses would equal the farm land in Britain, Germany and France combined.

\section{Mission Impossible}

One gets the increasing sense that environmental problems in total are mission impossible. Past sins are so grievous that they have put China in a massive hole. It would take the bulk of national resources to cure these past sins, much less improve the current situation. The CCP is simultaneously urging local governments to clean up the world, but at the same it continues to pressing forward at the maximum possible speed on economic development, creating hundreds of thousands of new pollution sources. The development of the 562 new coal powered plants is a classic case in point. It shows that environmentalism is one of the problems that can safely be handled by lip service and "correct" political rhetoric. But the economics of environmental losses may force finally them to change their policy. Even if this does happen, the situation remains the same - the gap is so enormous that it can't possibly be closed in the short run. So China will suffer for decades. Meanwhile, quietly, China has become the largest recipient of World Bank loans for environmental work, and the World Bank officially supports the Three Gorges Dam project and in fact, has funded one of the upstream dams.

Overall, the economic consequences of China's air and water pollution have been estimated at 3-8\% of GDP a year which approximates the highly touted growth rate of the whole economy. Great floods in 1996 were not only human disasters but cost \$25 billion in damages, and the 1998 floods were even worse impacting 240 million people and causing $\$ 70$ billion in damages. Acid rain is said to cost $\$ 700$ to 800 million each year, and air pollution an additional $\$ 55$ billion per year.

China is the world's largest user of coal for all purposes - one third of world consumption. Between 1978 and 1995, cities swelled by 180 million approved citizens, plus some 50 million unregistered migrants from the countryside. In small communities, lack of power has forced the use of hundreds of thousands of small inefficient industrial/commercial boilers and generators which account for one-third to one-half of emissions. Coal still produces $75 \%$ of all residential energy. Beijing has about $10 \%$ of the numbers of cars in L. A., but the emissions are about the same. Congenital obstructive pulmonary disease (COPD) is the leading 
cause of death in China, and it is five times more frequent than in the U. S. But China reasons that coal is cheap and locally produced; oil and gas are expensive, and much of it has to be imported at great cost. Recent increases in the price of oil have simply confirmed their faith in reliance on coal. The idea of a coal tax to constrain demand is stoutly resisted, since many coal users have no other options. The World Bank report goes on to describe many technological or managerial improvements that could be made, but they sound hollow, since all of them would take decades to disseminate very widely, and all would be extremely costly. The government likes to claim credit for closing down hundreds of thousands of small TVE establishments, but most of them were doomed anyway because they were so inefficient and amateurish. Besides, some of them competed with SOEs.

The medical insurance system covers less than $50 \%$ of the official urban population and less than $10 \%$ of the rural/small town population. Private spending on health care is the main source of funding - at least double that of public spending. But the costs of medical care are rapidly escalating and hundreds of millions of citizens simply do not have the money. Any serious health problems mean either no treatment or bankruptcy. The number of HIV infected exceeds the UN criteria for a "generalized epidemic", and the health care system can't cope. The health care system has almost no capacity to deal with such serious problems as heart disease, stroke, diabetes, or lung disease. Only $44 \%$ of the population has even rudimentary sanitary facilities, and fresh water is not available to $23 \%$ of the population. Preventative medicine is very rudimentary, and there are huge economic losses from worker medical and health problems such as heart disease, stroke and diabetes. And China is the world's largest consumer of tobacco products, with 320 million smokers.

Political leaders have learned to say the right things and lots of laws and regulations have been issued, but funds are scarce, and enterprises still bribe officials to look the other way. Environmental laws are seldom really enforced, and everybody knows it. There is a famous old Chinese saying: "The Mountains are high and the Emperor is far away."

But the disasters are building. Shanghai is in many respects modern China in miniature. Consider this example: in the late 90s, the river basin northwest of Shanghai, which contains 110 million people, suffered from a further massive pollution of an already polluted river. "Hundreds of thousands of people were left without drinking water, several thousand were treated for dysentery, diarrhea, and vomiting, and 26 million pounds of fish were killed." Pollution came from 1,000 factories: paper factories, leather, cloth dyeing, many more. Most were TVEs; most workers were migrants and moonlighters at slave wages. While the government forces the closure of these small business plants (60,000 in 1999), the larger SOEs are left alone. And still Shanghai continues to grow. 